\title{
How Long Should Adjuvant Chemotherapy Be Given in Early Stage Colon Cancer?
}

\section{Citation}

Retsky, Michael. 2013. “How Long Should Adjuvant Chemotherapy Be Given in Early Stage Colon Cancer?" Journal of Clinical \& Experimental Pathology 03 (01). doi:10.4172/2161-0681.1000136. http://dx.doi.org/10.4172/2161-0681.1000136.

\section{Published Version}

doi:10.4172/2161-0681.1000136

\section{Permanent link}

http://nrs.harvard.edu/urn-3:HUL.InstRepos:12559516

\section{Terms of Use}

This article was downloaded from Harvard University's DASH repository, and is made available under the terms and conditions applicable to Other Posted Material, as set forth at http:// nrs.harvard.edu/urn-3:HUL.InstRepos:dash.current.terms-of-use\#LAA

\section{Share Your Story}

The Harvard community has made this article openly available.

Please share how this access benefits you. Submit a story.

\section{Accessibility}


This is an open-access article distributed under the terms of the Creative Commons Attribution License, which permits unrestricted use, distribution, and reproduction in any medium, provided the original author(s) and source are credited.

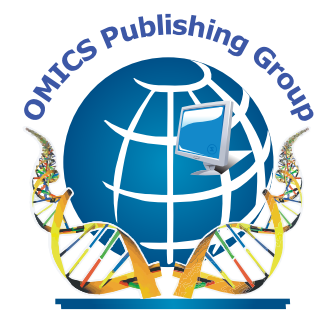

ISSN:2161-0681

\title{
Journal of Clinical \& Experimental Pathologyy
}

\author{
The International Open Access \\ Journal of Clinical \& Experimental Pathology \\ Executive Editors \\ Moges Woldemeskel \\ The University of Georgia, USA \\ Huamin Wang \\ The University of Texas, USA \\ C. Cameron Yin \\ UT MD Anderson Cancer Center, USA \\ Ozlen Saglam \\ Yale University, USA \\ John Hart \\ University of Chicago Medical Center, USA
}

\section{Available online at: OMICS Publishing Group (www.omicsonline.org)}

7 his article was originally published in a journal by OMICS

1 Publishing Group, and the attached copy is provided by OMICS Publishing Group for the author's benefit and for the benefit of the author's institution, for commercial/research/educational use including without limitation use in instruction at your institution, sending it to specific colleagues that you know, and providing a copy to your institution's administrator.

All other uses, reproduction and distribution, including without limitation commercial reprints, selling or licensing copies or access, or posting on open internet sites, your personal or institution's website or repository, are requested to cite properly. 


\title{
How long should Adjuvant Chemotherapy be given in Early Stage Colon Cancer?
}

\section{Michael Retsky*}

Harvard School of Public Health, Boston. MA 02115, USA

\begin{abstract}
After diagnosis of colon cancer, the tumor is removed and the stage of the disease is provided by a pathologist. If the stage indicates relatively high risk of relapse, adjuvant chemotherapy is used for 6 or so months to reduce the probability of such relapse. This is a very common situation in oncology - used for many early stage colon cancer patients of whom there will be 143,000 in 2013 in US. This therapy is only partially effective since 52,000 patients will die of metastatic colon cancer in 2013. Despite being used for decades, there is much room for improvement.
\end{abstract}

In May 2011, I published an editorial discussing my personal use of low dose, long term adjuvant chemotherapy for stage IIIc colon cancer in 1994-1997[1]. This therapy became known as metronomic chemotherapy. The question I now raise is: generally speaking, how long should adjuvant chemotherapy be used? I came to the following conclusion in 1994: If we assume first that cancer growth is well behaved, i.e., all cancer cells in the tumor divide once and only once during a doubling time, and second that the chemotherapy drug used is $100 \%$ effective, i.e., it kills every cell that tries to divide, then therapy duration should be one doubling time. Colon cancer volume doubling time is 2-3 months. Based on my estimates in 1994 of tumor behavior and drug 5-FU (5-Fluorouracil) effectiveness, I calculated chemotherapy should ideally be used longer than 2 years. Nobody could tolerate a toxic protocol for 2 years or more. Therefore, I used low dose infusional 5-FU therapy at a non-toxic level for 2.5 years. Thus this simple reasoning results in the conclusion that in order to be effective for all or nearly all cases, adjuvant chemotherapy for early stage colon cancer must be essentially nontoxic and used for over 2 years.

\section{Introduction}

Winquist and Boucher describe the lack of innovative new paths moving forward in cancer therapeutics as bleak with improvements often measured in months [2]. Given that 143,000 persons will be diagnosed and 52,000 patients will die of colon cancer in 2013 in the US, it is quite reasonable and appropriate to reconsider therapeutic concepts established long ago for the cancer treatment paradigm. In particular I will discuss here a reexamination of a long ago determined cancer therapeutic notion, i.e., the intensity and optimal duration of adjuvant chemotherapy after detection of early stage colon cancer.

As is the practice, after colon cancer is detected and diagnosed following screening colonoscopy, the patient is sent to a surgeon who removes the tumor and who then sends tissue removed to the pathology department. The pathologist examines the specimen and provides a report describing many details and listing the stage of the cancer. The report will particularly indicate the depth of penetration of the tumor into or through the bowel wall and how many relevant lymph nodes are found to contain cancer cells. Protein expressions that are known to have prognostic implications are also reported.

This information is then used by the medical oncologist who is the next physician in the treatment sequence. Given the patient's overall health and stage, a treatment is recommended that has been shown by clinical trial to reduce the probability of metastatic relapse for that stage colon cancer. Some patients will be cured by the simple removal of the primary tumor. Others will relapse at some time in the next 6-8 years.
In colon cancer, metastatic relapse is typically to the liver since there is a direct blood drain from the colon to the liver. Relapse usually, but not always these days, leads to eventual death from colon cancer and certainly is to be avoided if at all possible.

Stage II (basically node-negative) colon cancer is usually not given adjuvant therapy while stage III (node positive) colon cancer has higher risk of relapse and is usually given adjuvant therapy. The treatment meant to prevent relapse after surgical removal of the tumor is called surgical adjuvant therapy or simply adjuvant therapy. In the case of colon cancer, the mainstay therapy in 1994 when I was diagnosed with stage IIIc colon cancer was 5 -flourouracil for 6 months. This might be given with leukovorin which seemed to improve response somewhat. Relapse in 1994 virtually always led to death from the disease. Fortunately this is not always the result in 2013.

\section{Diagnosed with Stage IIIC Colon Cancer November 1994}

As a result of a routine physical exam in my early 50s, I had positive fecal occult blood tests twice which triggered colonoscopy in November 1994. I was awake at the end of the colonoscopy and saw a big ugly tumor on the display. I knew exactly what it was. I did not have to wait for the GI doc to explain it to me or see a report from pathology. There was no uncertainty or anxiety. While stage was yet unknown, I now had colon cancer. I had no family history of colon cancer; my parents lived until their late 80 s and early 90 s and died of normal diseases of the elderly and particularly not cancer. My two brothers were healthy. I always tried to lead a healthy life style with reasonable diet and exercise. I was trim and in good condition.

Surgery was a month or so later and we subsequently found that the stage was unexpectedly high. The tumor had penetrated the muscularis propria and into the pericolonic fat. There were four nodes positive and p53 was mutated. It was relatively easy to look up the prognosis. It was not good. In absence of therapy there was $80 \%$ chance of relapse

*Corresponding author: Michael Retsky, Harvard School of Public Health, Boston. MA 02115, USA, E-mail: michael.retsky@gmail.com

Received March 01, 2013; Accepted April 22, 2013; Published April 24, 2013

Citation: Retsky M (2013) How long should Adjuvant Chemotherapy be given in Early Stage Colon Cancer? J Clin Exp Pathol 3: 136. doi:10.4172/21610681.1000136

Copyright: (c) 2013 Retsky M. This is an open-access article distributed under the terms of the Creative Commons Attribution License, which permits unrestricted use, distribution, and reproduction in any medium, provided the original author and source are credited. 
and even with therapy there was still $50 \%$ chance of relapse. I had been doing research in breast cancer for a number of years and was on Judah Folkman's staff at Harvard Medical School so knew much about tumor growth and the theoretical underpinnings and evidence for intensive short course adjuvant chemotherapy. I knew in particular that the theory of using maximum tolerated drugs was based on the assumption that cancer growth was according to the Gompertz equation. This meant that tumor growth was fastest when the tumor was small and then growth gradually declined as the tumor enlarged. Thus therapy which was most effective when the cancer was rapidly growing should be given as soon as possible after diagnosis and surgery and at the highest tolerable level possible. After six or so months therapy ceases and we hope for the best.

The tumor growth theory was based on a study from the 1960 s by Laird $[3,4]$. I had studied the Laird papers in depth and came to the conclusion that these papers were hopelessly flawed. There were serious mathematical errors and the whole study was based on only 18 rodents and one rabbit. Because there were multiple species, Laird's conclusion was that the Gompertzian growth was a valid description of tumor enlargement in general. The mathematical flaw would have been detected by any college level student of mathematics. The Laird studies have been cited by well over 600 papers in the cancer literature. I came to the conclusion that none of these cancer researchers actually critically examined the Laird papers. They just assumed that the study was correct since it was published and so often cited. Or perhaps they did not know enough about elementary mathematics to find the errors. It is remarkable that something so key to oncology has not been given better scrutiny. There was an op-ed discussion in the New York Times [5] a few months ago claiming that the study of mathematics should be cut from curriculums in biology and medicine as not necessary in these modern times. I thought just the opposite. Perhaps over a million persons have been given maximum tolerated chemotherapy based on the mathematically flawed Laird papers.

Maximum tolerated chemotherapy also has links to key studies of Skipper and Schabel [6-8] in the 1960s and 1970s. Skipper and Schabel experimented with a leukemia animal model where the tumor grew exponentially with 1 day doubling time. This was convenient for experimentalists since a tumor could grow from one cell to a one centimeter tumor in 30 doubling times or one month. Skipper and Schabel could cure their animals after cancer was implanted if and only if they eradicated every last cancer cell and this could only be done with maximum tolerated chemotherapy. Their papers were laced with terms like LD-50 and LD-90 to indicate that the therapy they were using was lethal to $50 \%$ or $90 \%$ of the animals. The animals that survived the therapy were cured of cancer. Their papers included references to the Laird papers and stated that tumor growth was Gompertzian. I recall reading a discussion in one of their papers where they ask the rhetorical question if tumor growth might not be Gompertzian. Their answer was that it was possible but so unlikely that it was not worth considering. Skipper and Schabel papers were hugely influential in cancer science. Their papers have been cited over 2000 times. I was confident the entire philosophy of using maximum tolerated chemotherapy to cure cancer was based on flawed studies with key links to Laird papers and Skipper and Schabel papers. I knew the weaknesses in this theory and when my turn came, I sought to have a therapy that was based on more sturdy scientific foundation.

\section{Initial Use of Metronomic Chemotherapy}

Once I had made the decision not to use maximum tolerated chemotherapy I still had to find a therapy. After very useful information from Jack Speer, MD of Colorado Springs, who was a co-author of several papers with me, I contacted a few doctors in Eastern US where I then and still live. I was particularly impressed with William Hrushesky, MD who was at the time at a VA hospital in Albany, NY. Both Drs. Speer and Hrushesky had used infusional 5-FU for treatment of advanced colon cancer with some success in stabilizing the disease. I read everything available on the subject and eventually chose to use Dr. Hrushesky as the medical oncologist to design the therapy.

The therapy Dr. Hrushesky recommended was low dose infusional 5-FU. The dosage was 30\% reduction from the usually long term tolerable level of $300 \mathrm{mg} / \mathrm{meter}$-squared/day. Dr. Hrushesky was and still is very involved in the idea that chemotherapy should be given chrono-modulated, that is, during certain times of the day. He put me on a late afternoon to early evening schedule but I soon discovered that this was not going to work long term. As one example, I would go to a movie theater; while sitting in a quiet audience, every 90 seconds the pump would make an audible whirring noise. I read some papers and went to several conferences and found there was some disagreement on the exact best time of day to use chronomodulated chemotherapy.

I ended up using it when I went to bed at night and disconnecting in the morning. That made it much easier. I was on this therapy for about a year and was using 5 biomarkers to detect any early evidence of a relapse. There was no indication of impending relapse. I was confident the therapy was either killing the cancer cells, stabilizing the disease or there were no metastatic cancer cells in the liver to begin with. The situation was at least stable and I had to decide on how long to continue. At this point, the therapy was quite tolerable and I could stay on as long as necessary. However I needed a reasonable goal.

Giving it some thought, I arrived at a simple answer. Let's assume the tumor cells behaved like soldiers in a parade - each cell dividing once and only once in each volume doubling time. This would be a well behaved tumor. Now let's also assume the drug is perfect. That is while I am on 5-FU, any cancer cell that tries to divide will be killed. Under these ideal conditions, a well behaved tumor and a perfect drug, how long should chemotherapy be used? The answer is one volume doubling time which in the case of metastatic colon cancer is 2 or 3 months. I then derived a simple algebraic expression to allow me to calculate what would be the result of a less than perfect drug and/or a less than well behaved tumor. I had to make some reasonable estimates but if I wanted to be reasonably sure that the therapy worked, I arrived at the result that the therapy must be longer than 2 years.

This puts clear limits on how tolerable the therapy has to be. I seriously doubt many patients could tolerate a toxic therapy for two years. The therapy therefore must be essentially non-toxic. The simple conclusion is that in order to prevent all or almost all relapses in early stage colon cancer, the therapy must be given over 2 years and must therefore be non-toxic. I used low dose infusional 5-FU for 2.5 years. There was virtually no toxicity. My finger tips were soft and somewhat numb, there were minor cracks in the skin where my fingers flexed and I had one or two blood blisters in my mouth. My fingernails grew in coarsely but nothing else happened. I did not miss a day of work, vomited, or was in any discomfort. I exercised every day and felt fine.

I was on the staff of the late Judah Folkman while I was taking this low dose infusional 5-FU. I discussed my therapy with Dr. Folkman towards the end of the therapy in 1996 or 1997. Based on information from Dr. Speer and Dr. Hrushesky, it was apparent that low dose infusional 5-FU never seemed to stop working. This led me 
to think that perhaps the drug given in that way might have been at least partially antiangiogenic. At that time it was well recognized that chemotherapy drugs worked for a while and then seemed to stop working. This was inelegantly termed "drug resistance". It was also thought that antiangiogenic drugs did not develop drug resistance since the target vasculature was thought to have a stable genome as it was not malignant. Why then did low dose infusional 5-FU continue to work and not display drug resistance? I asked Judah Folkman if they ever tested low dose 5-FU for antiangiogenic properties. He brought Dr. Tim Browder into the room. Just the three of us were in the room. Browder had tested 5-FU and a number of other common cancer drugs for antiangiogenic properties but only given as bolus, never as I had used it. There was no indication of antiangiogenic activity. Folkman and Browder then decided that the therapy I was using should be tested for antiangiogenic action. It took about a year for this to happen. Browder had to implant special micro-pumps with 5-FU into tumor bearing mice. To great surprise it was partially antiangiogenic. Several other drugs were also antiangiogenic if given at low dose more or less continually. This was so unexpected that Browder had much difficulty getting a paper accepted stating these findings. Finally in April 2000 a paper was accepted and published in Cancer Research [9]. I was not listed as an author. Dr. Folkman however had me talk to Robert Cooke who was writing a biography of Dr. Folkman [10]. There are three pages in Cooke's book on my disease and therapy. Also Folkman introduced me on several occasions as the first human to use what was now called metronomic chemotherapy.

After I was off the therapy and was reasonably confident that it worked, I was very anxious to get the idea tested in a pilot study. Finally after asking Folkman for help in this, he took me to see the Medical head of Dan Farber Cancer Center. Thus I was in the Dana Farber chief's office with Judah Folkman and went through the story. The Dana Farber doc finally said I was probably cured by surgery and the low dose infusional 5-FU did nothing. After that disappointing experience, I lost much interest in pursuing the idea. If I couldn't get anything going with backing of Judah Folkman in front of the director of Dana Farber, who would do it? Another problem was that the drug was less expensive than sterile water so no pharmaceutical company would spend millions of dollars testing it if there was no financial reward at the end if it worked.

I wrote the 2011 editorial in frustration that the therapy was originally used in 1994 and while some investigation has been conducted, it was now 17 years later and it still has not gotten properly tested for adjuvant chemotherapy for early stage colon cancer as originally designed [11-14]. Now 2 years later, I am invited to a conference on treatment for metastatic colon cancer conducted by the Clinton Initiative - an influential organization. Maybe now something will happen. At any rate this document will describe the simple reasoning and requirements for adjuvant therapy to successfully treat stage IIIc colon cancer and perhaps the same logic applies to treatment of metastatic colon cancer. I was a participant on a cancer patient web site shortly after finishing therapy and found out that a patient with metastatic colon cancer used an almost identical therapy and her liver metastasis was completely eradicated. The patient was paraplegic and perhaps her physician decided she couldn't take a toxic therapy and thus he used low dose infusional 5-FU which couldn't hurt and might help. I reviewed her complete medical records and confirmed that low dose infusional 5-FU was the only therapy she had and metastatic hepatic tumors were eradicated. I lost touch with this person but have her records somewhere in my files if anybody wants to see them.
Judah Folkman and Tim Browder are both deceased since 2008 so I am the person left alive who can tell the story about the origins of metronomic chemotherapy and the reasoning underlying it.

Given this information and taking into consideration the scientific progress since 1994, how might we move forward? Recent studies have pointed out that colon cancer is a complex heterogeneous disease, developing through multiple genetic and epigenetic abnormalities, such as defective DNA Mismatch Repair (dMMR) and the CpG island Methylator Phenotype (CIMP) [15,16]. Adjuvant therapy is usually given to stage III patients but benefit to stage II colon cancer is debatable. Perhaps stage II would be a proper category to consider. Incidence of stage II colon cancer is $30-40 \%$ of all cases and relapse rate is approximately $15 \%$. The incidence will increase as screening programs are implemented. For most patients with stage II disease, who are classified as standard risk, there are no known markers to refine risk assessment or to predict adjuvant chemotherapy benefit. Recently Donada et al. suggested the use of molecular markers, such as TYMS and CIMP-High status to select high risk patients with stage II colon cancer who may benefit from adjuvant 5-FU therapy [17]. Given these findings, it might make sense to consider a clinical trial of high risk stage II colon cancer patients comparing metronomic with conventional 5-FU chemotherapy. If this is progressing favorably a similar trial for stage III might be reasonable.

\section{Acknowledgement}

This research was supported by a Grant from Susan B Komen. Michael Retsky is on the board of directors of the Colon Cancer Alliance (www.ccalliance.org) and has a patent pending for treatment of early stage cancer.

\section{References}

1. Retsky M, (2011) Metronomic Chemotherapy was Originally Designed and first used in 1994 for Early Stage Cancer - why is it taking so long to Proceed? J Bioequiv Availab 3:

2. Winquist RJ, Boucher DM (2010) Factors influencing development of new therapeutics for oncology. Curr Opin Pharmacol 10: 353-355.

3. Laird AK (1964) Dynamics of Tumor Growth. Br J Cancer 13: 490-502.

4. Laird AK (1969) Dynamics of growth in tumors and in normal organisms. Nat Cancer Inst Monogr 30: 15-28.

5. Andrew Hacker (2012) “Is Algebra Necessary?”Is Algebra Necessary?, New York Times.

6. Skipper HE, Schabel FM Jr, Trader MW, Laster WR Jr, Simpson-Herren L, et al. (1972) Basic and therapeutic trial results obtained in the spontaneous AK leukemia (lymphoma) model-end of 1971. Cancer Chemother Rep 56: 273287, 289-314.

7. Skipper HE, Schabel FM Jr, Mellett LB, Montgomery JA, Wilkoff LJ, et al. (1970) Implications of biochemical, cytokinetic, pharmacologic, and toxicologic relationships in the design of optimal therapeutic schedules. Cancer Chemother Rep 54: 431-450.

8. Skipper HE, Schabel FM Jr, Wilcox WS (1964) Experimental evaluation of potential anticancer agents. xiii. on the criteria and kinetics associated with "curability" of experimental leukemia. Cancer Chemother Rep 35: 1-111

9. Browder T, Butterfield CE, Kräling BM, Shi B, Marshall B, et al. (2000) Antiangiogenic scheduling of chemotherapy improves efficacy against experimental drug-resistant cancer. Cancer Res 60: 1878-1886.

10. Robert Cooke (2000), Dr Folkman's War: Angiogenesis and the Struggle to Defeat Cancer. ( $\left.1^{\text {stedn }}\right)$, Random House, New York, USA

11. Calvani N, Orlando L, Nacci A, Sponziello F, Cinefra M, et al. (2009) Metronomic chemotherapy against cancer: from paradigm to clinical practice? Tumori 95: 843-845.

12. Brandi G, de Rosa F, Bolondi L, Agostini V, Di Girolamo S, et al. (2010) Durable 
Citation: Retsky M (2013) How long should Adjuvant Chemotherapy be given in Early Stage Colon Cancer? J Clin Exp Pathol 3: 136. doi:10.4172/21610681.1000136

complete response of hepatocellular carcinoma after metronomic capecitabine. Tumori 96: 1028-1030.

13. Mutsaers AJ (2009) Metronomic chemotherapy. Top Companion Anim Med 24: $137-143$

14. Emmenegger U, Kerbel RS (2007) Five years of clinical experience with metronomic chemotherapy: achievements and perspectives. Onkologie 30: 606-608.
15. Jass JR (2007) Classification of colorectal cancer based on correlation of clinical, morphological and molecular features. Histopathology 50: 113-130.

16. Ogino S, Fuchs CS, Giovannucci E (2012) How many molecular subtypes? Implications of the unique tumor principle in personalized medicine. Expert Rev Mol Diagn 12: 621-628.

17. Donada M, Bonin S, Barbazza R, Pettirosso D, Stanta G (2013) Management of stage II colon cancer - the use of molecular biomarkers for adjuvant therapy decision. BMC Gastroenterol 13: 36
Citation: Retsky M (2013) How long should Adjuvant Chemotherapy be given in Early Stage Colon Cancer? J Clin Exp Pathol 3: 136. doi:10.4172/21610681.1000136
Submit your next manuscript and get advantages of OMICS Group submissions

\section{Unique features:}

ublishing

User friendly/feasible website-translation of your paper to 50 world's leading language Audio Version of published paper

Digital articles to share and explore

Special features:

250 Open Access Journals

20,000 editorial team

21 days rapid review process

Quality and quick editorial, review and publication processing

Indexing at PubMed (partial), Scopus, EBSCO, Index Copernicus and Google Scholar etc

Sharing Option: Social Networking Enabled

Authors, Reviewers and Editors rewarded with online Scientific Credits

Better discount for your subsequent articles

Submit your manuscript at: http://www.omicsonline.org/submission 